\title{
Reporting Innovations and Adaptations Employed for Statistical Evaluation of Efficacy of Human Embryonic Stem Cell Therapy in Spinal Cord Injury Cases
}

\author{
Short Title: Statistical Evaluation of hESC Therapy in Spinal Cord Injury \\ Dr. Geeta Shroff ${ }^{1}$, Dr. Jitendra Kumar Barthakur ${ }^{2}$ \\ ${ }^{1}$ Director, Nutech Mediworld, New Delhi, India
}

${ }^{2} \mathrm{PhD}$ Statistics, H.O.D., Department of Statistics, Nutech Mediworld, H-8, New Delhi, India

\begin{abstract}
The patients admitted in NUTECH Mediworld create a random and unbiased database. Forty-six symptoms assess spinal cord injury (SCI) cases. Each symptom has five ordinal grades; or Nutech Functional Score (NFS). NFS come in (.5, 5.5) ordinal range. A conversion to numeric $(0,1)$ range allows standard statistical tests. At admission, the scores are as (severe-many, mediumfewer and good-very few). After a few days of therapy, the scores alter to A-shape. The "normality"; and "homogeneity"of variance often compromise. The Institute uses "Empirical Bayes' Inference”.
\end{abstract}

Keywords: Bayes' Inference, Efficacy, Human-Embryonic-Stem-Cell-Therapy, Numeric-Scores, Spinal-Cord-Injury

\section{Introduction}

Institution administers hESC therapy usually to the chronic patients. SCI is the largest group of cases that had hESC therapy in the Institution. Institution had treated 277 SCI cases up to June 29, 2016; and had published four articles and seven books regarding handling of SCI.

In its quest to establish the truth of efficacy and safety of hESC therapy; and to be compliant to the principle of openness through a "good publication policy", which is the classical wish expected of a "good" medical institution, the Institution had attempted reporting their work right from the time when they started hESC therapy in 2005.

Over a decade and a year, the Institution had handled a number of issues affecting efficacy and safety of hESC therapy. The following two issues have no precedent of notice or resolution: (a) The question of randomness and bias of the database; and $(b)$ The tendency of the international community to work with categorical grades for diseases like SCI and cerebral palsy $(\mathrm{CP})$. The institution goes round (b) with a dissentient functional score grading the selected symptoms five ways. The grades are Nutech Functional Scores or NFS. NFS allows counting of cases for each symptom. (c) The grades are adjectives, or they are ordinal by construction in the range of $(.5,5.5)$; and can be converted to numeric values in the rage of $(0,1)$ to carry on usual statistical evaluation of the efficacy of hESC therapy. The testing of the hypothesis employing the method of R A Fisher and K Pearson becomes possible. However, not all attempts succeed.

The Institution considers that the use of "control groups "to disprove the theoretical incidence of the placebo effect of hESC therapy is not ethically acceptable. The Institution attempts to show that when the level of emendo takes the baseline scores higher by at least one NFS grade, after, of course, due validation with traditional statistical methods, with an accompanying show of alteration of the parabolic slope of scores at baseline to $\wedge$-shape at discharge, then the contention of placebo becomes redundant. In other words, working with "control group "becomes unnecessary.

Looking for a probabilistic alternative to establishing the experimental hypothesis when the data of scores is not bellshaped; or their dispersal is in variance is not homogeneous across the median values of the scores, the Institution provides a procedure to adjudge the "belief" of the cases in hESC therapy with an Empirical Bayes’ Inference.

These innovations and adaptations are in Paper15 of 2016 of the Institution, which is under the process of printing. This article reports the statistical methodology in brief.

\section{Randomness and bias}

The 226 SCI cases reported in Paper 15(DB1 or Database 1; reference period 24-August-2005 to 30-August-2012; 46 NFS symptoms for evaluation of the cases) have an average recorded or constructed history of more than five years of affliction with SCI before they come to the Institution for admission. They come on hearing about the Institution from mouth-to-mouth spread of information; and that the Institution dispenses a new therapy with hESC. They arrive without seeing an advertisement or hearing an announcement issued by or on behalf of the Institution. The cases are mainly Indians (113) who come from different states of India; 113 cases are from the 29 foreign countries (Australia31, USA-31, Iraq-6, Canada-5, Saudi Arabia-5, United Kingdom-5, Pakistan-4, Hongkong-3, Iran-2, Kuwait-2, Algeria-1, Argentina-1, Bangladesh-1, Brazil-1, Franch-1, Iceland-1, Mozambique-1, Nepal-1, NewZeland-1, Singapore- 


\section{International Journal of Science and Research (IJSR) \\ ISSN (Online): 2319-7064}

Index Copernicus Value (2016): 79.57 | Impact Factor (2015): 6.391

1, South Africa-1, South Korea-1, Spain-1, Srilanka-1, Sudan-1, Tanzania-1, Thailand-1, Turkey-1, UAE-1). Several cases under treatment are qualified doctors or members of the medical profession or members of medico families. 167 cases are males and 59 cases females. A few cases are rich but the others belong to middle-income groups, or they are poor. A few are scholars but most are with average education or no education. The cases satisfy the criterion of random arrivals.

An international list of SCI cases is not available. An international list of SCI cases that admit in hospitals after a given period following the spinal injury is also not available. Several SCI cases come to a specialised hospital, like to the Institution, well after the injury; and after undergoing essential surgery, physiotherapy and other types of medical service that the state or community provide to SCI at the time of injury. After this history, they arrive at a specialised hospital carrying the bias of having someone to bring them to the hospital and meet the cost of hospital fee, medicine and the expenses on other services. This bias exists everywhere in the world and for everyone admitted in a medical institution for prolonged and specialised treatment. Therefore, the random arrivals of the cases for admission in the Institute carry the same bias that the SCI cases do anywhere else in the world. The Institute has no exclusion criterion for admission of the SCI cases as in military hospital and in some other community-based hospitals. The cases admitted in the Institute constitute a random and unbiased database.

However, there is a flaw in the argument that since world is biased all over regarding SCI cases admitted in an specialised institution, the cases admitted in this Institute are unbiased arrivals by a majority opinion. The worldwide population of SCI cases admitted in a specialised medical institution needs carry a name such as SCI (hospitalised further) or SCI (HF).

\section{Nutech Functional Score}

The Institution had done the initial clinical assessment of the SCI cases with ASIA-IS, an intellectual property of the ASIA. ASIA allows the use of ASIA-IS to anyone who studies and reports matters related to "SCI".

ASIA-IS scales bear five grades, A, B, C, D and E that most of the medical institutions are familiar with these all over the world. After working with ASIA-IS, it became clear that the system required construction of (A, not-A); or (A, (B, C, D), E) anisotropic tuple branching as $(\mathrm{A}, \mathrm{B}, \mathrm{E})$ and $(\mathrm{A},(\mathrm{C}, \mathrm{D})$, E) for "sensory" and "power" syndromes. However, (A, notA)is the most commonly acceptable classification.

Facilities like ASIA-IS are not available for most other diseases that hESC include. The facilities for cerebral palsy (Institution had $146 \mathrm{CP}$ cases up to June 29, 2016) had the advantage of five International systems of assessment. A good number of these systems are age based.

- GMFCS- Gross Motor Functional Classification System; age base: $\leqq 18$ yrs

- MACS - Manual Ability Classification System; age base: 4-18 yrs
- PEDI - Paediatric Evaluation of Disability Inventory

- HRQOL- Health Related Quality of Life; inventory

- CFCS - Communication Function Classification System; age base: $2-18$ yrs

The Institution had used these international systems to assess the $\mathrm{CP}$ cases. The Institution published paper based on GMFCS.

Amyotrophic Lateral Sclerosis or ALS (24 cases as on June $29,2016)$ has the international scale of ALS-FRS-R - Functional Rating Scale - Revised, that stages as many as 125 symptoms.

Multiple Sclerosis or MS has the international Disability Scale EDSS, which is Expanded Disability Status Scale, when expanded. (34 cases of MS as on June 29, 2016)

ESS is European Stroke Scale for Cerebrovascular Accident, or CVA, that base on 14 symptoms and gives out more or less a subjective grade; and the grading is dependent upon the opinion of the attending physician. (67 cases of CVA as on June 29, 2016)

These international ways of grading the cases intend to be of help in deeper study of the concerned disease. However, they do not ordinarily lead to a comprehensive statistical evaluation of efficacy of the therapy in question.

NFS has five grades. Grades are 1, 2, 3, 4 and 5; and they are adjectives. Grades go from BAD to GOOD and imply BAD, (NOT SO BAD), (MEDIUM), (NOT SO GOOD) and (GOOD); or $1 \rightarrow 5$. Grade 5 implied "almost cure" and of course, also, "cure" or "normal" in common medical usage when a case scoring $<5$ at admission, scores 5 at discharge. A case could never score Grade 5 at admission. Every patient suffered from at least one symptom out of several symptoms that defined the disease.

The Institution defines SCI with 46 NFS symptoms. These create three principal tables of count.

Table 1 answers the query asking "How many cases, who scored less than the Highest Possible Score", or HPG, or scored less than 5 in NFS, "at admission and how many of them scored HPG onany later visit?" Every group of cases, like "all cases", "Paraplegia, "Quadriplegia" or "Cases that had at least one hundred days of treatment" and so on, can have a separate Table1. The underlying strength of this query lies in the belief that SCI cases never cure. The HPG score in NFS means the "normal" condition or cure of a case, or a condition very close to the condition of cure.

Table 1 relating to "All SCI Cases" appends. An extract to it displays the weighted averages that suggest that around 6\% of the cases scored HPG at the end of the hESC therapy. The number of cases that the symptom had affected provided the weights. The aggregative "weighted average" condensed the all-ness of the symptoms. The result indicates the efficacy of hESC therapy that performs the "miracle" of cure within a limited number of days of therapy albeit for a limited number of cases.

\section{Volume 6 Issue 12, December 2017} www.ijsr.net

Licensed Under Creative Commons Attribution CC BY 


\section{International Journal of Science and Research (IJSR) \\ ISSN (Online): 2319-7064}

Index Copernicus Value (2016): 79.57 | Impact Factor (2015): 6.391

Table 2 answers the query as to "How many cases scored less than HPG in NFS at admission and that admissionscores remained unaltered at the end of the hESC therapy; and how many altered their admission-score to a higher NFS level at the end of the therapy?" Every group of cases produces, as in the case of Table 1, a separate Table 2. Table 2 for "All cases" is appended; and it shows that the count of the cases that altered their admission score to a higher discharge level was about $95 \%$ of the cases. This query partly answers the miracle that the SCI cases come seeking for when they came to the Institution for admission. No one becomes worse off after hESC therapy; a very few stay without any improvement; however, $95 \%$ become better off at least by one grade of NFS!

Table 3 serves the query, "Which higher grade the cases had reached after hESC therapy?" for every symptom in every group of the SCI cases, as in the cases of Table 1 and Table 2. A copy of Table 3 for "All Cases" and three most predominant symptoms is appended.

There is also Table 4 that validates Table 1, Table 2 and Table 3 for the group of "All Cases". Table 4 is appended after the last symptom is displayed in Table3.

\section{Numeric NFS}

Symptoms are names and they cannot have a fixed place for ranking without additional information qualifying the symptoms; like the number of cases that a symptom affects. Consequently, a case cannot have a fixed place, platero, in the assidere or elaborate arrangement of information in a database, because symptoms define a case and symptoms have no rank. However, NFS grades mean order like BAD, NOTSO-BAD, MEDIUM, NEARLY-GOOD and GOOD, or they are adjectives. The grades can convert to numeric entities within a fixed numeric range. Then grade becomes score; symptoms get rank and cases get rank for each other, platero.

The conversion takes the easiest possible path. A hypothetical set of adjective scores starting at " 0.5 " in the range of $(0.5,5.5)$ is one straight line; and another straight line starts at " 0 " in the range $(0,1)$ of a numeric set. " 5.5 " of the adjective range equates to " 1 " of the numeric scale. That makes the slope of the adjective line .5; and the point of intersection .5; in $(y=.5 x-.5)$. This line has $\mathrm{R}^{2}=1$ or no deviation off the original NFS adjective values. For a similar straight line for the numeric grades, the slope is .096; and the intersection .166; in $(y=.096 x-.166)$ with $\mathrm{R}^{2}=.994$, which is pretty close to 1 .

$$
\text { Whence, } \frac{Y_{c}+0.5}{0.5}=x=\frac{Y_{n}+0.166}{0.096} \text { for }
$$

$\mathrm{Y}_{\mathrm{c}}=$ adjective or categorical grade; and

$$
\mathrm{Y}_{\mathrm{n}}=\text { numeric score. }
$$

The exercise produces a conversion table as given below for five grades defining a symptom.

\begin{tabular}{|c|c|c|c|c|c|}
\hline Score & \multicolumn{5}{|c|}{ CONVERSION TABLE } \\
\hline Categorical & 1 & 2 & 3 & 4 & 5 \\
\hline Numeric & 0.122 & 0.310 & 0.500 & 0.690 & 0.879 \\
\hline Range (Numeric) & $(0, .241)$ & $(>.241$, & $(>.379$, & $(>.621$, & $(>.759,1)$ \\
& & $.379)$ & $.621)$ & $.759)$ & \\
\hline
\end{tabular}

For conversion to three grades like for $\langle\mathrm{A}, \mathrm{B}, \mathrm{E}\rangle$ and $\langle\mathrm{A}$, (C, D), E> for ASIA-IS or generally for the grades of < BAD, MEDIUM, GOOD>can use the table as given below:

\begin{tabular}{|c|c|c|c|}
\hline Score & \multicolumn{3}{|c|}{ CONVERSION TABLE } \\
\hline Categorical & 1 & 2 & 3 \\
\hline Numeric & 0.167 & 0.500 & 0.833 \\
\hline Range (Numeric) & $(0, .333)$ & $(>.333, .667)$ & $(.667,1)$ \\
\hline
\end{tabular}

These tables help a case carry a definite numeric score as identity, platero, for myriads of analytical exercises. One use is to convert back to categorical identity using the numeric range of the values as given in the last row of the two tables. Such conversions produce "putative grades". Table 4 that the putative grades produced had verified the overall findings of Table 1, Table 2 and Table 3 that, as mentioned earlier, based on direct counting of the cases that a number of symptoms had affected.

\section{Normality and homogeneity of variance:}

However, the conditions of normality and homogeneity of variance do not prevail for all score variables every time. Ordinarily, majority of cases that NFS numeric scores estimateat admission, or at baseline, appear (BAD) or (NOT SO $\mathrm{BAD})$ rather than (MEDIUM), (NOT SO GOOD) or (GOOD). That makes the baseline data acquire a shape that differs intrinsically from the normal curve. No transformations of the baseline data can make the look alter even remotely to a normal curve. Later, the shape of the distribution of the data alters. After the time-periods, T1 and T2, the data may leave behind the U-shape of baseline and acquire a $\Lambda$-shape; but usually, it stays skewed to the left. After T3, the distribution often shows kurtosis. After T4 the distribution skews towards the opposite direction because the number of (NOT SO GOOD) and (GOOD) cases may outstrip the (BAD), (NOT SO BAD) and (MEDIUM) cases. This statistical situation fingers towards an inherent theory that hESC therapy alters the conditions of the cases who undertake the therapy. The results of counting indicate that no case ever become worse off than before. Therefore, the assumption can be that hESC therapy alters the cases for the better. Upon that, a few statistical issues surface.

\section{Attrition of cases visit after visit:}

Firstly, there is attrition of the patients at every stage of discharges. $\mathrm{N}$ cases at baseline or $\mathrm{T} 0$ remain as $\mathrm{N}$ at the end of T1. However, not all return to do the second spell, T2, of the therapy. In the same way, the cases become fewer for T3, T4, .... . For example, 226 SCI cases at baseline became twenty after T4.

A new variable "last visit" bears the time connotation TL, "L" standing for "last". TL permits a working method to handle attrition of the cases. The number of cases at T0, T1 and TL remain the same $\mathrm{N}$. TL can be $\mathrm{T} 1, \mathrm{~T} 2, \ldots$. That allows comparison of the scores at T0 with the scores at TL. Of course, it is always possible to construct score variable relating to (T0, T1, T2) by excluding the scores of those cases who did not come back for T2 from the list covering T0 and T1. Similarly, series of score variable can relate to (T0, T1, T2, T3), (T0, T1, T2, T3, T4) and so on.

\section{Volume 6 Issue 12, December 2017}




\section{International Journal of Science and Research (IJSR) \\ ISSN (Online): 2319-7064}

Index Copernicus Value (2016): 79.57 | Impact Factor (2015): 6.391

Then again, the innovation of shorter series of the cases attracts the issue of sensitivity of Kolmogorov-Smirnov Test (KS Test) and Levene's Test (Lev Test). The sensitivity of these tests becomes intense when the sample size is big, like 226 cases. On the other hand, they are not so sensitive when the sample size is small, like twenty cases of (T0, T1, T2, T3, T4). Commercial computer programmes display normality or homogeneity of variance of the data regardless of the size of N. Should that allow reliance placed on the "sameness" of testing a hypothesis for 226 cases and twenty cases?

\section{Testing of hypotheses}

Whenever the data allowed, the hypothesis $\mathrm{H}$ employed is "cases emend with hESC therapy"; and $\mathrm{H}$ is likely to happen after showing that the null-hypothesis $\mathrm{N}_{\mathrm{A}}$ that "Cases emend with hESC therapy by chance" is unlikely to happen with $p$ value 5 and $95 \%$ level of confidence. Classical statistics presents several ways to test the likelihood of $\mathrm{H}$. Working accordingly, validation followed variously that $\mathrm{N}_{\mathrm{A}}$ is unlikely to happen and therefore, $\mathrm{H}$ is likely to happen. That shows the prowess and the usefulness of the numeric form of NFS. However, a classical $N_{B}$ states, "Cases emend in spite of hESC therapy". For disproving $\mathrm{N}_{B}$ the medical overseers desire that there must be a control group that suffer a "false therapy" without the knowledge of the cases selected for the "false therapy" and the result of the "false therapy" or placebo should be shown as different and inferior compared to the cases who receive the "real therapy". The Institution in their Ethics Committee refuses to indulge in falsity and say "no". Statistics finds a way to diminish $\mathrm{N}_{\mathrm{B}}$ by showing that $\mathrm{N}_{\mathrm{B}}$ is probabilistically redundant under a very common circumstance that the average of the variable score increases monotonously in time; and can never become $<.122$ in value in a range of $(0,1)$ at admission. This is because a patient is not a dead body; and there are means to say that the patient is alive even if the patient has no motor or sensory function. The essence of $\mathrm{N}_{\mathrm{B}}$ is the concept of prior probability:A case becomes "better" by itself and hESC therapy has nothing to do with it. The probability study on $\mathrm{N}_{\mathrm{B}}$ eventually led to the use of Bayes' Inference as a readymade method to show that efficacy of hESC therapy is established with the emendo which is opposite of placebo.

\section{Redundancy of $\mathrm{N}_{\mathrm{B}}$ :}

Paper 14 of 2015 (Footnote (ii) (6)) had first reported this finding at its Appendix IV. The numeric figures used relate to Paper 14 and they stay unaltered.

The experimental hypothesis $\mathrm{H}$ works on a "universally true" condition of

\section{SCORE (0) $\uparrow \operatorname{SCORE~(1933)~} \uparrow \operatorname{SCORE}(2029)$}

where " 0 " means the day of affliction that caused SCI; "1933" is the number of days that intervenes admission of the case in the Institution after affliction; "2029" is the number of days after " 0 " when the case was assessed after a spell of $(2029-1933=) 96$ days of hESC therapy; and " $\uparrow "$ means "average increases to".
The real life figures are

$\{$ Score $(0)=0.122\} \uparrow\{$ Score $(1933)=0.3438\} \uparrow\{$ Score $(2029)=0.5029\}$ in Paper 14 .

Consider two straight lines: One is (A) and it connects 0.122 with 0.3438 across the abscissa 1933 on the $\mathrm{x}$-axis. The other is (B) and it connects 0.122 with 0.5029 across the abscissa 2029, which is $96 \mathrm{hESC}$ treatment days away from 1933 treatment days. Taking the route of ordinates, (i) an ordinate at 1933 days on (A) reads as $(.3438-.122=) .2218$ above .122. Similarly, (ii) an ordinate at 2029 days on (B) will read as (.5029-.122=).3809 above .122. Roughly, hESC had added (.3809-.2258=).1551 after 96 days of hESC treatment.

These are always true if $\uparrow$ is true.

That gives a ready reckoning of probability of emendo with hESC as $\frac{.122}{1551}=.7866$. The contra is $1-.7866=.2134$ producing the odd of emendo as $\frac{.7866}{.2134}=3.69$ or that cases emend about 4 times better with hESC therapy as compared to the cases of emendo without hESC therapy.

However, some require area based estimates. Consider a diagram of rectangle with $(.122 \times 2029=) 247.6$ units of area. Right triangle R1 standing on it with base 2029 and $(.3438-.122=) .2218$ height in continuity of one breadth of the rectangle will have the area of $\left(\frac{.2218 \times 2029}{2}=\right) 225.0$. Right triangle R2 standing on the rectangle with base 2029 and $(.5029-.122=) .3809$ height in continuity with one width of the rectangle, as described before, will have the area of $\left(\frac{3809 \times 2029}{2}=\right)$ 386.4. That gives the area of emendo without hESC as $(247.6+225.0=) 472.6$ and the area of emendo with hESC as $(247.6+386.4=) 634.0$ giving emendo as $\left(\frac{472.6}{634.0}=\right) .7454$. The contra is $1-.7454=.2546$ producing the odd of emendo as $\frac{.7454}{.2546}=2.9$ or it is about 3 times that hESC emends better with hESC compared to the cases of emendo without hESC.

In addition, the net area of emendo with hESC is (634.0 $427.6=) 206.4$ while net area of emendo without hESC is 225.0 giving the odd of $\left(\frac{206.4}{225.0}=\right) .9173$. The contra is $(1-$ $.9173=) .0827$ or if the area at the baseline of affliction is ignored and only the natural emendo over the baseline of affliction is taken into consideration, then the odd is $\frac{.9173}{.0827}=$ 11.09 or about 11 times that hESC emends better compared to the cases emend without hESC. This estimate is logically more valid because the assumption of the value of .122 for all symptoms at affliction is an idea. Any value higher than .122 at the baseline of affliction will depress the angle

[The slope of $\mathrm{A}$ is $\tan ^{-1} \alpha,\{\alpha=(.3438-.122=) .2218 / 1933=)$ $\left.1.11 \times 10^{-4}\right\}$ ] And consequently, the reading of the area of emendo without hESC treatment will move downward enhancing, in comparison, the value of the area of emendo with hESC treatment.

Therefore, the inbuilt strength of the logical structure of the clinical investigation renders $\mathrm{N}_{\mathrm{B}}$ redundant.

\section{Volume 6 Issue 12, December 2017}




\section{International Journal of Science and Research (IJSR) \\ ISSN (Online): 2319-7064 \\ Index Copernicus Value (2016): 79.57 | Impact Factor (2015): 6.391}

\section{Empirical Bayes' Inference:}

In attempt made to exhibit the redundancy of $\mathrm{N}_{\mathrm{B}}$ the concept of prior probability and the posterior probability has been used. These two are the substantial parts of Bayes' Inference that military and space research (USER1) have made famous.

The word "probability" conveys an attitude of mind and the word relates to a proposition " $q$ " to query whether " $q$ " is true. The logical state to relate " $q$ " only to $q$ 's of a particular type that are members of "population" " $p$ " of which " $q$ " is proposition.

The probability of proposition $q$ and data $p$ is $P(q \mid p)$.

If $n$ mutually exclusive propositions $q_{1} \ldots q_{\mathrm{n}}$ on data $p$ are $P_{1}$ $\ldots P_{\mathrm{n}}$, then the probability on data $p$ that one of them is true is $P_{1}+P_{2}+\ldots+P_{\mathrm{n}}$.

Let $\mathrm{q}_{1} \ldots \mathrm{q}_{\mathrm{n}}$ are alternative propositions, $\mathrm{H}$ is the information available, $\mathrm{p}$ some additional information, then

$P\left(q_{i} \mid H\right)=P(p \mid H) P\left(q_{i} \mid p H\right)=P\left(q_{i} \mid H\right) P\left(p \mid q_{i} H\right)$

If the truth of one of the $q$ 's is certain, it can be derived that $P\left(q_{i} \mid p H\right) \propto P\left(q_{i} \mid H\right) P\left(p \mid q_{i} H\right)$.

The probability of $q_{i}$ on data $p$ and $H$ is proportional to the product of that of $q_{i}$ on $H$ and $p$ on $q_{i}$ and $H$.

In this Bayes' Theorem, let $H$ be data known before event happens, so that $H$ is the basis on which the relative probabilities of $q$ 's are judged. Let event happen. The probability of $q_{i}$ after the event had happened varies as the probability before it had happened, multiplied by the probability that it happened on data $q_{i}$ and $H$.

The probability $P\left(q_{i} \mid p H\right)$ is the posterior probability.

$P\left(q_{i} \mid H\right)$ is the prior probability.

$P\left(p \mid q_{i} H\right)$ is the likelihood.

Bayes' Postulate says that, if there are no reasons to consider that qi's are unequal, then all qi's are equal, say, equal to q. In other words,

$P(q \mid p H)=P(q \mid H) P(p \mid q H)$.

Using this axiomatic approach of taking probability as a measure of mind, the prior probabilities are equal because nothing is known about them. One principal objection is that one must know which frequency distribution provides equal frequency from which actual $q$ emanate. There is no answer to that question. Yet, the acceptance of the Bayes' Postulate yields good results for USER1, who infer that the probability of $\mathrm{q}_{i}$ 's having one value of $\mathrm{q}$ is very high because the successes of its applications indicate so; and they call this doing the Bayes' Inference (without licence !!).

Working on the presumption that no SCI case comes for hESCT while the case is at a "zero" state or at a state that the case is alive but it has no motor or sensory function at all, the grade at admission must be at least " 1 " in the NFS categorical scale. To apply Bayes' Inference likeUSER1, or the probability of the SCI scoring at least 1 at admission is almost a surety, a case needs score on a later discharge at least " 2 " in NFS grade. This is equivalent to saying that GAIN is $>.122$ in NFS numeric scale with the range as $(0,1)$. In other words, every case has a prior "not-zero" ability to emend that provides an estimate of the degree of the "prior not-zero ability". This prior probability is "q".

Operationally, a table of two score variables and one temporal variable has (i) average NFS numeric score of ' $x$ ' at BASELINE, (ii) average NFS numeric score of ' $y$ ' at any discharge and (iii) ' $\mathrm{T}$ ', the average days of hESCT; $(\mathrm{y}-\mathrm{x})=\mathrm{d}$ $>.122$ in NFS numeric scale.

Experience shows that while " $x$ " is never normal; " $y$ " infrequently is. On the other hand, " $d$ " distributes normally; however, not always.

The numeric NFS scores in the range of $(0,1)$ in the conversion table are the mid-points of the five numeric ranges. The first range is $(0, .241)$ and its mid-point is .122; $(\mathrm{x}-.122=)$ 'a1' and $(\mathrm{y}-.122=)$ 'b1'. The difference $(\mathrm{b} 1-\mathrm{a} 1=)$ is' $\mathrm{d}$ '.

An extended straight line (SL) joining the values of the average scores of $\mathrm{b} 1$ with those a1 of BASELINE in the $(++)$ quadrant intersecting the $(-+)$ quadrant at the point $(t, 0)$; giving the relation

$$
\begin{aligned}
& \frac{a 1}{t}=\frac{b 1}{t+T}, \text { whence } \\
& \mathrm{t}=\frac{a 1 \times T}{b_{1}-a_{1}} \text { days ago or "ago". }
\end{aligned}
$$

The time equivalence to prior probability is " $\mathrm{t}$ " and of posterior probability is " $\mathrm{T}$ ". If $\mathrm{t}>\mathrm{T}$, then the test of $\mathrm{H}$ is immature. hESC therapy should go on for a greater length of time to show result. Alternately, $\mathrm{N}_{\mathrm{A}}$ is true for hESC therapy for $\mathrm{T}$ days.

Half of the rectangle-like (a1 $\mathrm{x} \mathrm{t})$ is outside the area that hESCT covers, and its value is $\left(\frac{1}{2} \times\right.$ a1 $\left.x \mathrm{t}\right)$, which is the externality of the inputs of $\mathrm{x}, \mathrm{y}$ and $\mathrm{T}$. As against it, the internality of $(\mathrm{x}, \mathrm{y}, \mathrm{T})$ is

$$
\begin{gathered}
\{1 / 2 *(\mathrm{a} 1+\mathrm{b} 1) * \mathrm{~T}\}+\{1 / 2 * \mathrm{~d} * \mathrm{~T}\} \\
\text { or } \quad 1 / 2 *(\mathrm{a} 1+\mathrm{b} 1+\mathrm{d}) * \mathrm{~T} . \\
\text { Clearly, prior probability is } \\
P(A)=\frac{\text { Externality }}{\text { Internality }+ \text { Externality }}=\mathrm{p} 1 .
\end{gathered}
$$

In other words, the given " $\mathrm{n}$ " cases had about $\mathrm{p} 1 \%$ ability to emend prior to their admission in the Institution.

If $\theta$ is the angle of intersection of SL with the $\perp$ defined as $x$ $=.122$; then

$$
\theta=\tan ^{-1}\left(\frac{d}{T+t}\right) \text { or } \theta=\text { " } \rho " \text { radian or }
$$

' $\delta$ ' degrees.

The estimate of $P(B)$ when the maximum value of the score " 1 ", is

$$
\begin{aligned}
& \tan ^{-1}\left(\frac{1-.122}{d}\right)=\varphi \text { degrees, } \\
& \text { giving } \frac{\theta}{\theta+\varphi}=\mathrm{p}_{2}
\end{aligned}
$$

or $\mathrm{p}_{2} \%$ is the ambit of $(\mathrm{x}, \mathrm{y}, \mathrm{T})$ within the internal and the external ambits of hESCT.

This is an abstraction. It states that the likelihood of the angle inside the sweep of hESCT is about $\mathrm{p}_{2}$, which is the marginal likelihood or the posterior probability $P(B)$ of the data on hand.

This direct method differs from the expected practice of USER1 treating B distributed as normal or any other known

\section{Volume 6 Issue 12, December 2017}




\section{International Journal of Science and Research (IJSR) \\ ISSN (Online): 2319-7064}

Index Copernicus Value (2016): 79.57 | Impact Factor (2015): 6.391

probability distribution whose segments are calculable and thus capable of giving out a theoretical value for $\mathrm{P}(\mathrm{B})$.

Turning to the conditional probability $P(A \mid B)$, which is event A happening for B happened, a number of trials showed that determination of $P(A \mid B)$ from the first principles is not easy. Eventually, a simple solution espied in seeing that when $P(B \mid A)=1$, then

$$
(P(A) / P(B))=P(A \mid B) .
$$

When $P(B \mid A) \neq 1$, then $P(A) / P(B)$ needs carrya factor like $\frac{T}{T+t}$ to estimate $\mathrm{P}(\mathrm{A} \mid \mathrm{B})$; with a relationship like $\mathrm{P}(\mathrm{A} \mid \mathrm{B})=(\mathrm{P}(\mathrm{A}) / \mathrm{P}(\mathrm{B})) *\left(\frac{T}{T+t}\right)$.

$\left(\frac{T}{T+t}\right)$ is potent and called "therapy factor". $\mathrm{T}$ is the temporal cause of emendo after hESC therapy; $t$ is the temporal cause of ability to emend before hESC therapy. "Therapy factor" is same as $\mathrm{P}(\mathrm{B} \mid \mathrm{A})$. That provides a bit of food-forthought. Even if $\mathrm{P}(\mathrm{B} \mid \mathrm{A})$ is $\left(\frac{T}{T+t}\right)$ without epistemological expansiveness, it is a good data-based entity, which is different, but not very different from the logic of USER1 in assuming that $\mathrm{P}(\mathrm{A})$ is constant for $\mathrm{q}$.

By inspection, $\left(\frac{t}{T+t}\right)$ is the factor of ability to emend without hESC therapy for the exact temporal distance of $\mathrm{T}$. It is same as $\mathrm{P}(\mathrm{A} \mid \mathrm{B})$; however, not exactly. Employment of the factors of $\left(\frac{T}{T+t}\right)$ and $\left(\frac{t}{T+t}\right)$ remain empirical until more rigorous proof establishes firstly the Bayes' Postulate; and secondly, justifies the two factors.

Empirical Bayes' Inference comes to work and adds to the older paths leading to testing $\mathrm{H}$ for saying "hESC therapy benefits SCI cases". The first table that came out is about GR3 SCI 95 or the 95 SCI who discontinued hESC after T1 = 57 days. GR3 had resisted every trick with which a hypothesis could stand established. In these calculations $\left(\frac{T}{T+t}\right)$ estimates $\mathrm{P}(\mathrm{B} \mid \mathrm{A})$. $\mathrm{P}(\mathrm{A} \mid \mathrm{B})$ is then derived with Bayes' Postulate.

\section{BAYES' INFERENCE}

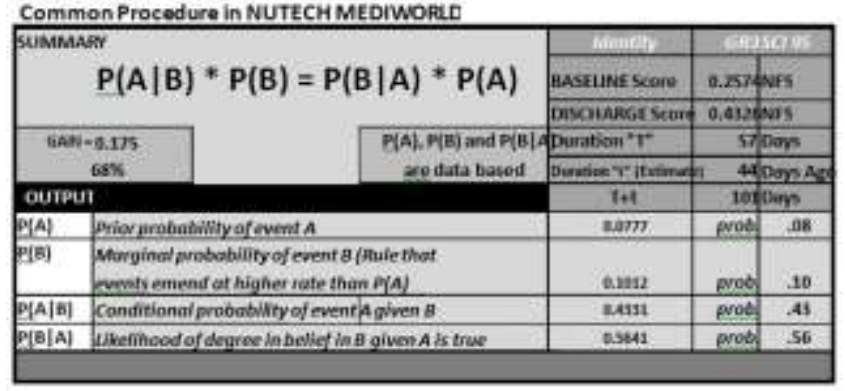

\section{Conclusions}

The option of treating the patients admitted in a medical institution as random and unbiased entities has logical support.

In order to establishing the fidelity of hESC therapy, the Institute has explored the available paths that confirm the efficacy of a clinical aim. The statistical evaluation finds the system of grading a symptom affecting SCI in five ordinal grades as good. The ordinal grades allow counting of cases by symptoms and then preparing a condensed picture for consideration.

Because the grades are ordinal, they convert to numeric grades in the range $(0,1)$ from its categorical range of $(.5$, 5.5). This beneficial innovation opens path practically towards all tests that probability based literature has constructed.

To get round the issue of propensity of most of the score variables being not normal or scedastically homogenous, the Institution has developed, thirdly, a ready and supportive way to adjudge efficacy with Empirical Bayes' Inference. This development benefits the science of medicine in comprehending the results of clinical work and practices

\section{Future Scope}

As in all other research fields, the research system in Nutech Mediworld developed with observation, application and results derived.

In the database of spinal cord injury patients, a patient carries the unique identity in age, history of ailment, gender and past records. However, the institutional assessment of the SCI patient with NFS is in grades and symptoms of medical sciences. Grades define symptom and symptoms define patient. That led to several problems in statistical validation of efficacy of a given line of treatment such as with human embryonic stem cells in emending SCI.

The paper reports how the institution went round the problems that had surfaced almost about ten years ago. The research will continue. On receiving comments on the paper, review and necessary alterations will be made.

\section{References}

[1] NUTECH MEDIWORLD, is a twenty-bedded medical facility at H8, Green Park Extension in New Delhi, India.

[2] Shroff G. Human Embryonic Stem Cells in the Treatment of Patients with Spinal Cord Injury. Ann Neurosci.2015;22:208-216.

[3] Shroff G. Role of Anesthetists in Human Embryonic Cells Transplantation in Patients with Spinal Cord Injury. J Anesth Clin Res. 2015;6:5.

[4] Shroff G. Human Embryonic Cells in Treatment of Spinal Cord Injury: A Prospective Study. J Neurol Res. 2015;5:213-220.

[5] Shroff G. Bowel/Bladder Sensation and Control in Patients with Spinal Cord Injury Treated with Human Embryonic Stem Cell therapy. EC Neurology. 2015;2.1:47-54.

[6] Shroff G. Clinical Study Report - Retrospective Study of Human Embryonic Stem Cell (HESC) Therapy in Patients with Spinal Cord Injury. NUTECH Mediworld. 2010;2:60.

[7] Barthakur JK, Shroff G. Human Embryonic Stem Cells Therapy Spinal Cord Injury; A Pilot Study of 72 Cases. NUTECH Mediworld. 2010;3:273. 


\section{International Journal of Science and Research (IJSR) \\ ISSN (Online): 2319-7064}

Index Copernicus Value (2016): 79.57 | Impact Factor (2015): 6.391

[8] Barthakur JK, Shroff G. Safety and Efficacy of Human Embryonic Stem Cell Transplantation (2002-2004). NUTECH Mediworld. 2006;4:36.

[9] Barthakur JK, Shroof G. Human Embryonic Stem Cell Therapy - Chronic Spinal Cord Injury Cases. NUTECH Mediworld. 2012;10:207.

[10] Barthakur JK, Shroff G. Human Embryonic Stem Cell Therapy - Chronic Spinal Cord Injury Cases - Descriptive Statistics. NUTECH Mediworld. 2011;12:274.

[11] Barthakur J K. A Statistical Comparison and Evaluation of Spinal Cord Injury Cases with Asia Impairment Scale and NUTECH Functional Score; (Medical Statistics). NUTECH Mediworld. 2015;14:216.

[12] Barthakur J K. A Statistical Assessment of Human Embryonic Stem Cell Therapy in Spinal Cord Injury with Emendo of Paraplegia and Quadriplegia. NUTECH Mediworld. 2016;15:261.

\section{Author Profile}

Dr. Jitendra Kumar Barthakur is a doctor of philosophy $(\mathrm{PhD})$ in (Statistics) from the University of Gauhati, India. He started his carrier in Indian Frontier Administrative Service, 1959 Batch in the Ministry of External Affairs in the Government of India and retired in 1988 from the rank of Additional Secretary to the Government of India (equivalent to military rank of Lt. General commanding a corps of the Indian Army). After retirement he joined as Consultant to the Government of Nagaland for Block Development Programme and Consultant to the Government of Mizoram for suggesting Marketing of the produce of the Cooperative Societies for assessing Block Development Programme.

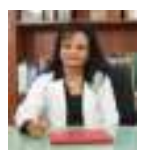

Dr. Geeta Shroff is an infertility expert and she is the very first individual to develop an infinite number of pure human embryonic stem cell lines from using just one embryo. Dr. Shroff's treatment is ground breaking. Every day we hear about other treatments around the globe regarding stem cells (fetal, umbilical cord, nasal, rats, mice etc.) and Dr. Geeta Shroff has developed the only purely human embryonic stem cell lines that do not show any immune reaction in the body. Embryonic stem cells do not have any antigenic proteins on their surface and thus do not require immunosuppressant drugs. Dr. Shroff's technology involved the use of just ONE embryo. During her laboratory research she only used surplus embryos from an IVF donor who underwent a barrage of tests including a complex medical history and genetic history. 
International Journal of Science and Research (IJSR)

ISSN (Online): 2319-7064

Index Copernicus Value (2016): 79.57 | Impact Factor (2015): 6.391

Table 1: All cases: Calculation of weighted average

\begin{tabular}{|c|c|c|}
\hline Arithmetic & Value & What value signifies \\
\hline $\mathrm{X}=\Sigma(\mathrm{T} * \mathrm{C})$ & 457949 & $\begin{array}{c}\text { Summation of the products of the Treatment Days and the } \\
\text { Count of the affected cases. }\end{array}$ \\
\hline$\Sigma\left(\mathrm{T} *\left(\mathrm{~T}_{*} \mathrm{C}\right) / \mathrm{X}\right)$ & 98 & Ave Days of Treatment TAST \\
\hline$\Sigma\left(\mathrm{C} *\left(\mathrm{~T}_{*} \mathrm{C}\right) / \mathrm{X}\right)$ & 165 & Ave. Number of Affected Cases TAST \\
\hline$\Sigma\left(<\mathrm{HPG}\right.$ at Baseline $\left.*\left(\mathrm{~T}_{*} \mathrm{C}\right) / \mathrm{X}\right)$ & 165 & Ave. number of $<$ HPG at Baseline TAST \\
\hline$\Sigma\left(\mathrm{Net}\right.$ HPG at End of Therapy $\left.\left(\mathrm{T}_{*} \mathrm{C}\right) / \mathrm{X}\right)$ & 9 & Ave. Net HPG at the end of Therapy TAST \\
\hline $\begin{array}{c}\% \text { of Net HPG at the End of Therapy to }<\mathrm{HPG} \text { at } \\
\text { Baseline }\end{array}$ & 5.77 & Per cent TAST \\
\hline
\end{tabular}

TAST is "Taking All Symptoms Together".

Table 1 (all cases): Number of cases that scored less than the highest possible grade $(<\mathrm{hpg})$ at baseline but reached highest possible grade on later visit

\begin{tabular}{|c|c|c|c|c|c|c|c|}
\hline \multirow{3}{*}{ Symptoms, Case (BL) } & \multirow{3}{*}{$\begin{array}{c}\text { Average } \\
T D L \\
(T)\end{array}$} & \multirow{3}{*}{$\begin{array}{c}\text { Affected } \\
\text { Cases } \\
(C)\end{array}$} & \multicolumn{2}{|c|}{ Baseline } & \multicolumn{2}{|c|}{ End of Therapy } & \multirow{3}{*}{$\begin{array}{c}\% \text { of } \mathrm{Col}(7) \text { to } \mathrm{Col} \\
\text { (4) }\end{array}$} \\
\hline & & & \multirow{2}{*}{$<H P G$} & \multirow{2}{*}{$H P G$} & \multirow{2}{*}{$\begin{array}{l}\text { Gross } \\
\text { HPG } \\
\end{array}$} & \multirow{2}{*}{$\begin{array}{c}\mathrm{Net} \\
\mathrm{HPG} \\
\end{array}$} & \\
\hline & & & & & & & \\
\hline$(1)$ & $(2)$ & $(3)$ & (4) & $(5)$ & (6) & (7) & $(8)$ \\
\hline Bed Sore Number, 35 & 120 & 35 & 35 & 0 & 21 & 21 & 60.00 \\
\hline Bed Sore Size, 35 & 120 & 35 & 35 & 0 & 20 & 20 & 57.14 \\
\hline Bulk/ Limb Atrophy L/L L, 175 & 96 & 175 & 175 & 0 & 10 & 10 & 5.71 \\
\hline Bulk/ Limb Atrophy L/L R, 173 & 97 & 173 & 173 & 0 & 10 & 10 & 5.78 \\
\hline Bulk/ Limb Atrophy U/L L, 64 & 107 & 64 & 64 & 0 & 10 & 10 & 15.63 \\
\hline Bulk/ Limb Atrophy U/L R, 64 & 106 & 65 & 65 & 0 & 9 & 9 & 13.85 \\
\hline Control Bladder, 209 & 98 & 209 & 209 & 0 & 5 & 5 & 2.39 \\
\hline Control Bowel, 203 & 98 & 203 & 203 & 0 & 4 & 4 & 1.97 \\
\hline Deep Sensation, 204 & 96 & 204 & 204 & 0 & 10 & 10 & 4.90 \\
\hline Flaccidity L/L L, 40 & 94 & 40 & 40 & 0 & 4 & 4 & 10.00 \\
\hline Flaccidity L/L R, 40 & 94 & 40 & 40 & 0 & 4 & 4 & 10.00 \\
\hline Flaccidity U/L L, 10 & 102 & 10 & 10 & 0 & 0 & 0 & 0.00 \\
\hline Flaccidity U/L R, 10 & 102 & 10 & 10 & 0 & 0 & 0 & 0.00 \\
\hline $\begin{array}{l}\text { Flaccidity with Muscular Contracture } \\
\text { L/L L, } 47\end{array}$ & 89 & 47 & 47 & 0 & 2 & 2 & 4.26 \\
\hline $\begin{array}{l}\text { Flaccidity with Muscular Contracture } \\
\text { L/L R, } 48\end{array}$ & 90 & 48 & 48 & 0 & 3 & 3 & 6.25 \\
\hline $\begin{array}{l}\text { Flaccidity with Muscular Contracture } \\
\text { U/L L, } 6\end{array}$ & 107 & 6 & 6 & 0 & 2 & 2 & 33.33 \\
\hline $\begin{array}{l}\text { Flaccidity with Muscular Contracture } \\
\text { U/L R, } 6\end{array}$ & 107 & 6 & 6 & 0 & 2 & 2 & 33.33 \\
\hline Hand Grip U/L L, 92 & 104 & 92 & 92 & 0 & 23 & 23 & 25.00 \\
\hline Hand Grip U/L R, 93 & 104 & 93 & 93 & 0 & 20 & 20 & 21.51 \\
\hline Plantar Reflex L/L L, 217 & 95 & 217 & 217 & 0 & 3 & 3 & 1.38 \\
\hline Plantar Reflex L/L R, 217 & 95 & 217 & 217 & 0 & 3 & 3 & 1.38 \\
\hline Power L/L L, 221 & 96 & 221 & 221 & 0 & 11 & 11 & 4.98 \\
\hline Power L/L R, 221 & 96 & 221 & 221 & 0 & 9 & 9 & 4.07 \\
\hline Power U/L L, 96 & 104 & 96 & 96 & 0 & 38 & 38 & 39.58 \\
\hline Power U/L R, 93 & 104 & 93 & 93 & 0 & 34 & 34 & 36.56 \\
\hline Sensation Bladder, 204 & 99 & 204 & 204 & 0 & 8 & 8 & 3.92 \\
\hline Sensation Bowel, 200 & 99 & 200 & 200 & 0 & 8 & 8 & 4.00 \\
\hline Spasticity L/L L, 52 & 103 & 52 & 52 & 0 & 4 & 4 & 7.69 \\
\hline Spasticity L/L R, 52 & 103 & 52 & 52 & 0 & 5 & 5 & 9.62 \\
\hline Spasticity U/L L, 13 & 131 & 13 & 13 & 0 & 3 & 3 & 23.08 \\
\hline Spasticity U/L R, 13 & 131 & 13 & 13 & 0 & 2 & 2 & 15.38 \\
\hline Spasticity with Clonus L/L L, 83 & 97 & 83 & 83 & 0 & 6 & 6 & 7.23 \\
\hline Spasticity with Clonus L/L R, 82 & 97 & 82 & 82 & 0 & 6 & 6 & 7.32 \\
\hline Spasticity with Clonus U/L L, 13 & 126 & 13 & 13 & 0 & 3 & 3 & 23.08 \\
\hline Spasticity with Clonus U/L R, 16 & 119 & 16 & 16 & 0 & 4 & 4 & 25.00 \\
\hline Spasticity with Deformity L/L L, 50 & 100 & 50 & 50 & 0 & 4 & 4 & 8.00 \\
\hline Spasticity with Deformity L/L R, 50 & 100 & 50 & 50 & 0 & 4 & 4 & 8.00 \\
\hline Spasticity with Deformity U/L L, 8 & 97 & 8 & 8 & 0 & 0 & 0 & 0.00 \\
\hline Spasticity with Deformity U/L R, 9 & 96 & 9 & 9 & 0 & 0 & 0 & 0.00 \\
\hline Spinal Gait L/L L, 220 & 96 & 220 & 220 & 0 & 14 & 14 & 6.36 \\
\hline Spinal Gait L/L R, 220 & 96 & 220 & 220 & 0 & 13 & 13 & 5.91 \\
\hline Superficial Sensation, 200 & 97 & 200 & 200 & 0 & 8 & 8 & 4.00 \\
\hline Tendon Reflex L/L L, 214 & 96 & 214 & 214 & 0 & 5 & 5 & 2.34 \\
\hline
\end{tabular}


International Journal of Science and Research (IJSR)

ISSN (Online): 2319-7064

Index Copernicus Value (2016): 79.57 Impact Factor (2015): 6.391

\begin{tabular}{|c|c|c|c|c|c|c|c|}
\hline \multirow{3}{*}{ Symptoms, Case (BL) } & \multirow{3}{*}{$\begin{array}{c}\text { Average } \\
\text { TDL } \\
(T)\end{array}$} & \multirow{3}{*}{$\begin{array}{c}\text { Affected } \\
\text { Cases } \\
(C)\end{array}$} & \multicolumn{2}{|c|}{ Baseline } & \multicolumn{2}{|c|}{ End of Therapy } & \multirow{3}{*}{$\begin{array}{c}\% \text { of Col (7) to Col } \\
\text { (4) }\end{array}$} \\
\hline & & & \multirow{2}{*}{$<H P G$} & \multirow{2}{*}{$H P G$} & \multirow{2}{*}{$\begin{array}{l}\text { Gross } \\
H P G\end{array}$} & \multirow{2}{*}{$\begin{array}{c}\mathrm{Net} \\
\mathrm{HPG}\end{array}$} & \\
\hline & & & & & & & \\
\hline$(1)$ & $(2)$ & (3) & (4) & $(5)$ & $(6)$ & (7) & $(8)$ \\
\hline Tendon Reflex L/L R, 215 & 96 & 215 & 215 & 0 & 5 & 5 & 2.33 \\
\hline Tendon Reflex U/L L, 60 & 102 & 60 & 60 & 0 & 13 & 13 & 21.67 \\
\hline Tendon Reflex U/L R, 60 & 102 & 60 & 60 & 0 & 11 & 11 & 18.33 \\
\hline
\end{tabular}

Table 2: All cases: Calculation of weighted average.

\begin{tabular}{|c|c|c|}
\hline Arithmetic & Value & What value signifies \\
\hline $\mathrm{X}=\Sigma(\mathrm{T} * \mathrm{C})$ & 457949 & Summation of the products of the Treatment Days and the Count of the affected cases. \\
\hline$\Sigma\left(\mathrm{T} *\left(\mathrm{~T}_{*} \mathrm{C}\right) / \mathrm{X}\right)$ & 98 & Ave Days of Treatment TAST \\
\hline$\Sigma\left(\mathrm{C} \mathrm{X}\left(\mathrm{T}_{*} \mathrm{C}\right) / \mathrm{X}\right)$ & 165 & Ave. Number of Affected Cases TAST \\
\hline$\Sigma($ Cases (Alteration: Worse $\left.\left.) * \mathrm{~T}_{*} \mathrm{C}\right) / \mathrm{X}\right)$ & 0.00 & Ave. Cases (Alteration: Worse) at the end of Therapy TAST \\
\hline$\Sigma($ Cases (Alteration: No change $\left.) *\left(\mathrm{~T}_{*} \mathrm{C}\right) / \mathrm{X}\right)$ & 40 & Ave. Cases (Alteration: No change) at the end of Therapy TAST \\
\hline$\Sigma($ Cases (Alteration: Better $\left.))^{*}\left(\mathrm{~T}_{*} \mathrm{C}\right) / \mathrm{X}\right)$ & 125 & Ave. Cases (Alteration: Better) at the end of Therapy TAST \\
\hline \% of Alteration: Worse & 0.00 & Per cent TAST \\
\hline \% of Alteration: No Change & 24 & Per cent TAST \\
\hline \% of Alteration: Better & 86 & Per cent TAST \\
\hline
\end{tabular}

TAST is "Taking All Symptoms Together".

Table 2 (all cases): Number of cases by symptoms that scored differently later by at least one grade of NFS compared to the scores at baseline

\begin{tabular}{|c|c|c|c|c|c|c|c|c|}
\hline \multirow[t]{2}{*}{ Symptoms, Case (BL) } & \multirow{2}{*}{$\begin{array}{c}\begin{array}{c}\text { Average } \\
\text { TDL }\end{array} \\
\text { (T) }\end{array}$} & \multirow{2}{*}{$\begin{array}{c}\text { Affected } \\
\text { Cases } \\
\text { (C) }\end{array}$} & \multicolumn{3}{|c|}{$\begin{array}{c}\text { Alteration in SCORE at least by } \\
1 \text { Grade }\end{array}$} & \multicolumn{3}{|c|}{$\begin{array}{c}\% \text { of Alteration in SCORE at } \\
\text { least by } 1 \text { Grade }\end{array}$} \\
\hline & & & Worse & No Change & Better & Worse & No Change & Better \\
\hline (1) & (2) & (3) & (4) & (5) & (6) & (7) & (8) & (9) \\
\hline Bed Sore Number, 35 & 120 & 35 & 0 & 9 & 26 & 0.00 & 25.71 & 74.29 \\
\hline Bed Sore Size, 35 & 120 & 35 & 0 & 8 & 27 & 0.00 & 22.86 & 77.14 \\
\hline Bulk/ Limb Atrophy L/L L, 175 & 96 & 175 & 0 & 45 & 130 & 0.00 & 25.71 & 74.29 \\
\hline Bulk/ Limb Atrophy L/L R, 173 & 97 & 173 & 0 & 45 & 128 & 0.00 & 26.01 & 73.99 \\
\hline Bulk/ Limb Atrophy U/L L, 64 & 107 & 64 & 0 & 11 & 53 & 0.00 & 17.19 & 82.81 \\
\hline Bulk/ Limb Atrophy U/L R, 64 & 106 & 65 & 0 & 11 & 54 & 0.00 & 16.92 & 83.08 \\
\hline Control Bladder, 209 & 98 & 209 & 0 & 96 & 113 & 0.00 & 45.93 & 54.07 \\
\hline Control Bowel, 203 & 98 & 203 & 0 & 109 & 94 & 0.00 & 53.69 & 46.31 \\
\hline Deep Sensation, 204 & 96 & 204 & 0 & 54 & 150 & 0.00 & 26.47 & 73.53 \\
\hline Flaccidity L/L L, 40 & 94 & 40 & 0 & 5 & 35 & 0.00 & 12.50 & 87.50 \\
\hline Flaccidity L/L R, 40 & 94 & 40 & 0 & 5 & 35 & 0.00 & 12.50 & 87.50 \\
\hline Flaccidity U/L L, 10 & 102 & 10 & 0 & 2 & 8 & 0.00 & 20.00 & 80.00 \\
\hline Flaccidity U/L R, 10 & 102 & 10 & 0 & 2 & 8 & 0.00 & 20.00 & 80.00 \\
\hline $\begin{array}{c}\text { Flaccidity with Muscular Contracture } \\
\text { L/L L, } 47\end{array}$ & 89 & 47 & 0 & 10 & 37 & 0.00 & 21.28 & 78.72 \\
\hline $\begin{array}{c}\text { Flaccidity with Muscular Contracture } \\
\text { L/L R, } 48\end{array}$ & 90 & 48 & 0 & 10 & 38 & 0.00 & 20.83 & 79.17 \\
\hline $\begin{array}{c}\text { Flaccidity with Muscular Contracture } \\
\text { U/L L, } 6\end{array}$ & 107 & 6 & 0 & 0 & 6 & 0.00 & 0.00 & 100.00 \\
\hline $\begin{array}{c}\text { Flaccidity with Muscular Contracture } \\
\text { U/L R, } 6\end{array}$ & 107 & 6 & 0 & 0 & 6 & 0.00 & 0.00 & 100.00 \\
\hline Hand Grip U/L L, 92 & 104 & 92 & 0 & 14 & 78 & 0.00 & 15.22 & 84.78 \\
\hline Hand Grip U/L R, 93 & 104 & 93 & 0 & 13 & 80 & 0.00 & 13.98 & 86.02 \\
\hline Plantar Reflex L/L L, 217 & 95 & 217 & 0 & 87 & 130 & 0.00 & 40.09 & 59.91 \\
\hline Plantar Reflex L/L R, 217 & 95 & 217 & 0 & 87 & 130 & 0.00 & 40.09 & 59.91 \\
\hline Power L/L L, 221 & 96 & 221 & 0 & 26 & 195 & 0.00 & 11.76 & 88.24 \\
\hline Power L/L R, 221 & 96 & 221 & 0 & 23 & 198 & 0.00 & 10.41 & 89.59 \\
\hline Power U/L L, 96 & 104 & 96 & 0 & 11 & 85 & 0.00 & 11.46 & 88.54 \\
\hline Power U/L R, 93 & 104 & 93 & 0 & 9 & 84 & 0.00 & 9.68 & 90.32 \\
\hline Sensation Bladder, 204 & 99 & 204 & 0 & 55 & 149 & 0.00 & 26.96 & 73.04 \\
\hline Sensation Bowel, 200 & 99 & 200 & 0 & 75 & 125 & 0.00 & 37.50 & 62.50 \\
\hline Spasticity L/L L, 52 & 103 & 52 & 0 & 6 & 46 & 0.00 & 11.54 & 88.46 \\
\hline Spasticity L/L R, 52 & 103 & 52 & 0 & 6 & 46 & 0.00 & 11.54 & 88.46 \\
\hline Spasticity U/L L, 13 & 131 & 13 & 0 & 1 & 12 & 0.00 & 7.69 & 92.31 \\
\hline Spasticity U/L R, 13 & 131 & 13 & 0 & 1 & 12 & 0.00 & 7.69 & 92.31 \\
\hline Spasticity with Clonus L/L L, 83 & 97 & 83 & 0 & 21 & 62 & 0.00 & 25.30 & 74.70 \\
\hline Spasticity with Clonus L/L R, 82 & 97 & 82 & 0 & 21 & 61 & 0.00 & 25.61 & 74.39 \\
\hline
\end{tabular}


International Journal of Science and Research (IJSR)

ISSN (Online): 2319-7064

Index Copernicus Value (2016): $79.57 \mid$ Impact Factor (2015): 6.391

\begin{tabular}{|c|c|c|c|c|c|c|c|c|}
\hline Spasticity with Clonus U/L L, 13 & 126 & 13 & 0 & 2 & 11 & 0.00 & 15.38 & 84.62 \\
\hline Spasticity with Clonus U/L R, 16 & 119 & 16 & 0 & 2 & 14 & 0.00 & 12.50 & 87.50 \\
\hline Spasticity with Deformity L/L L, 50 & 100 & 50 & 0 & 18 & 32 & 0.00 & 36.00 & 64.00 \\
\hline Spasticity with Deformity L/L R, 50 & 100 & 50 & 0 & 18 & 32 & 0.00 & 36.00 & 64.00 \\
\hline Spasticity with Deformity U/L L, 8 & 97 & 8 & 0 & 5 & 3 & 0.00 & 62.50 & 37.50 \\
\hline Spasticity with Deformity U/L R, 9 & 96 & 9 & 0 & 5 & 4 & 0.00 & 55.56 & 44.44 \\
\hline Spinal Gait L/L L, 220 & 96 & 220 & 0 & 13 & 207 & 0.00 & 5.91 & 94.09 \\
\hline Spinal Gait L/L R, 220 & 96 & 220 & 0 & 13 & 207 & 0.00 & 5.91 & 94.09 \\
\hline Superficial Sensation, 200 & 97 & 200 & 0 & 49 & 151 & 0.00 & 24.50 & 75.50 \\
\hline Tendon Reflex L/L L, 214 & 96 & 214 & 0 & 81 & 133 & 0.00 & 37.85 & 62.15 \\
\hline Tendon Reflex L/L R, 215 & 96 & 215 & 0 & 81 & 134 & 0.00 & 37.67 & 62.33 \\
\hline Tendon Reflex U/L L, 60 & 102 & 60 & 0 & 22 & 38 & 0.00 & 36.67 & 63.33 \\
\hline Tendon Reflex U/L R, 60 & 102 & 60 & 0 & 21 & 39 & 0.00 & 35.00 & 65.00 \\
\hline
\end{tabular}

Table 3: Movement of SCI cases from lower NFS grades to higher NFS grades symptom: power 1/1 1 (all cases)

\begin{tabular}{|c|c|c|c|c|c|c|c|c|}
\hline \multirow{3}{*}{ Level } & \multirow{3}{*}{ Description } & \multicolumn{4}{|c|}{ Cases at } & & & \\
\hline & & \multirow{2}{*}{ Baseline } & (a) End of & \multicolumn{2}{|c|}{ (b) End of } & & & \\
\hline & & & First Period & \multicolumn{2}{|c|}{ Therapy } & & & \\
\hline 1 & No Power & 168 & 26 & \multicolumn{2}{|c|}{11} & & & \\
\hline 2 & Flicker or contraction only & 24 & 125 & \multicolumn{2}{|c|}{95} & & & \\
\hline 3 & Movement with gravity eliminated & 14 & 37 & \multicolumn{2}{|c|}{72} & & & \\
\hline 4 & Discernible movement against gravity & 15 & 27 & \multicolumn{2}{|c|}{32} & & & \\
\hline 5 & Moderate to full movement against gravity or reached normalcy & 0 & 6 & \multicolumn{2}{|c|}{11} & & & \\
\hline & Total & 221 & 221 & \multicolumn{2}{|c|}{221} & & & \\
\hline \multicolumn{2}{|r|}{ Explanation (a) } & & & & & & & \\
\hline \multirow{3}{*}{ Level } & \multirow{3}{*}{ Description } & \multicolumn{7}{|c|}{ Explanation of change (Cases at the end of First Period) } \\
\hline & & No & Changed to & \multirow{2}{*}{1} & \multirow{2}{*}{2} & \multirow{2}{*}{3} & \multirow{2}{*}{4} & \multirow{2}{*}{5} \\
\hline & & change & higher level & & & & & \\
\hline 1 & No Power & 26 & 142 & $\mathrm{x}$ & 111 & 28 & 3 & 0 \\
\hline 2 & Flicker or contraction only & 14 & 10 & $\mathrm{x}$ & $\mathrm{x}$ & 8 & 2 & 0 \\
\hline 3 & Movement with gravity eliminated & 1 & 13 & $\mathrm{x}$ & $\mathrm{x}$ & $\mathrm{x}$ & 13 & 0 \\
\hline 4 & Discernible movement against gravity & 9 & 6 & $\mathrm{x}$ & $\mathrm{x}$ & $\mathrm{x}$ & $\mathrm{x}$ & 6 \\
\hline 5 & Moderate to full movement against gravity or reached normalcy & 0 & 0 & $\mathrm{x}$ & $\mathrm{x}$ & $\mathrm{x}$ & $\mathrm{x}$ & $\mathrm{x}$ \\
\hline & Total & 50 & 171 & 0 & 111 & 36 & 18 & 6 \\
\hline \multicolumn{2}{|c|}{ Explanation $(b)$} & & & & & & & \\
\hline \multirow{3}{*}{ Level } & \multirow{3}{*}{ Description } & \multicolumn{7}{|c|}{ Explanation of change (Cases at the end of Therapy) } \\
\hline & & $\mathrm{No}$ & Changed to & \multirow{2}{*}{1} & \multirow{2}{*}{2} & \multirow{2}{*}{3} & \multirow{2}{*}{4} & \multirow{2}{*}{5} \\
\hline & & change & higher level & & & & & \\
\hline 1 & No Power & 11 & 157 & $\mathrm{x}$ & 87 & 61 & 9 & 0 \\
\hline 2 & Flicker or contraction only & 8 & 16 & $\mathrm{x}$ & $\mathrm{x}$ & 10 & 5 & 1 \\
\hline 3 & Movement with gravity eliminated & 1 & 13 & $\mathrm{x}$ & $\mathrm{x}$ & $\mathrm{x}$ & 12 & 1 \\
\hline 4 & Discernible movement against gravity & 6 & 9 & $\mathrm{x}$ & $\mathrm{x}$ & $\mathrm{x}$ & $\mathrm{x}$ & 9 \\
\hline 5 & Moderate to full movement against gravity or reached normalcy & 0 & 0 & $\mathrm{x}$ & $\mathrm{x}$ & $\mathrm{x}$ & $\mathrm{x}$ & $\mathrm{x}$ \\
\hline & Total & 26 & 195 & 0 & 87 & 71 & 26 & 11 \\
\hline
\end{tabular}

Note: Relates to 221 SCI cases that the symptom "Power L/L R" had affected at Admission out of 226 total SCI cases in DB1.

Table 4: SCI, 226 allcasesspinal cord injury Movement of SCI cases from lower putative grades to higher putative grades Baseline to End of Period 1 and End of Therapy

\begin{tabular}{|c|c|c|c|c|}
\hline Numeric Range & \multirow{2}{*}{$\begin{array}{c}\text { NFS Putative Grade } \\
\text { Equivalence of Range }\end{array}$} & \multicolumn{3}{|c|}{ Cases at } \\
\cline { 3 - 5 } & & Baseline & $\begin{array}{c}(a) \text { End of } \\
\text { First Period 1 }\end{array}$ & $\begin{array}{c}(b) \text { End of } \\
\text { Therapy }\end{array}$ \\
\hline $0-.241$ & 1 & 126 & 26 & 5 \\
\hline $.242-.379$ & 2 & 76 & 97 & 64 \\
\hline $.380-.621$ & 3 & 22 & 91 & 131 \\
\hline $.622-.759$ & 4 & 2 & 9 & 21 \\
\hline $.760-1$ & 5 & 0 & 3 & 5 \\
\hline \multicolumn{2}{r}{ Total } & 226 & 226 & 226 \\
\hline
\end{tabular}

\begin{tabular}{|l|l|l|l|l|l|l|l|l|}
\hline \multirow{3}{*}{ Numeric Range } & NFS Putative Grade & Explanation (a) \\
\cline { 5 - 9 } & Equivalence of Range & No change & Changed to higher level & \multicolumn{5}{|c|}{ Levels } \\
\cline { 4 - 9 } & & & & 1 & 2 & 3 & 4 & 5 \\
\hline $0-.241$ & 1 & 26 & 100 & $\mathrm{x}$ & 68 & 32 & 0 & 0 \\
\hline
\end{tabular}


International Journal of Science and Research (IJSR)

ISSN (Online): 2319-7064

Index Copernicus Value (2016): 79.57 Impact Factor (2015): 6.391

\begin{tabular}{|l|l|l|l|l|l|l|l|l|}
\hline $.242-.379$ & 2 & 29 & 47 & $\mathrm{x}$ & $\mathrm{x}$ & 44 & 3 & 0 \\
\hline $.380-.621$ & 3 & 15 & 7 & $\mathrm{x}$ & $\mathrm{x}$ & $\mathrm{x}$ & 6 & 1 \\
\hline $.622-.759$ & 4 & 0 & 2 & $\mathrm{x}$ & $\mathrm{x}$ & $\mathrm{x}$ & $\mathrm{x}$ & 2 \\
\hline $.760-1$ & 5 & 0 & 0 & $\mathrm{x}$ & $\mathrm{x}$ & $\mathrm{x}$ & $\mathrm{x}$ & $\mathrm{x}$ \\
\hline Total & 70 & 156 & 0 & 68 & 76 & 9 & 3 \\
\hline
\end{tabular}

Explanation (b)

\begin{tabular}{|c|c|c|c|c|c|c|c|c|}
\hline \multirow[t]{3}{*}{ Numeric Range } & \multirow{3}{*}{$\begin{array}{l}\text { NFS Putative Grade } \\
\text { Equivalence of Range }\end{array}$} & \multicolumn{7}{|c|}{ Explanation of change (Cases at the end of Therapy) } \\
\hline & & \multirow[t]{2}{*}{ No change } & \multirow[t]{2}{*}{ Changed to higher level } & \multicolumn{5}{|c|}{ Levels } \\
\hline & & & & 1 & 2 & 3 & 4 & 5 \\
\hline $0-.241$ & 1 & 5 & 121 & $\mathrm{X}$ & 54 & 62 & 5 & 0 \\
\hline $.242-.379$ & 2 & 10 & 66 & $\mathrm{x}$ & $\mathrm{x}$ & 59 & 7 & 0 \\
\hline $.380-.621$ & 3 & 10 & 12 & $\mathrm{x}$ & $\mathrm{x}$ & $\mathrm{x}$ & 9 & 3 \\
\hline $.622-.759$ & 4 & 0 & 2 & $\mathrm{x}$ & $\mathrm{x}$ & $\mathrm{x}$ & $\mathrm{x}$ & 2 \\
\hline $.760-1$ & 5 & 0 & 0 & $\mathrm{x}$ & $\mathrm{X}$ & $\mathrm{x}$ & $\mathrm{X}$ & $\mathrm{x}$ \\
\hline \multicolumn{2}{|r|}{ Total } & 25 & 201 & 0 & 54 & 121 & 21 & 5 \\
\hline
\end{tabular}

